\title{
Lexico-semantic relativity and versatility in translation and intercultural communication
}

\author{
Victor V. KABAKCHI ${ }^{1}$ and Zoya G. PROSHINA ${ }^{2}$ \\ ${ }^{1}$ Herzen State Pedagogical University of Russia \\ St. Petersburg, Russia \\ ${ }^{2}$ Lomonosov Moscow State University \\ Moscow, Russia
}

\begin{abstract}
The aim of the article is to discuss translation regularities in correlations of words that denote culture-related phenomena that exist in many cultures or that are specific to certain cultures and languages. The focus is on Russian and English culturonyms. The authors dwell on the principle of functional dualism that claims that language can equally address internal and external cultures. This principle is developed in the new linguistic discipline termed "interlinguoculturology" (Kabakchi 1998, Kabakchi \& Beloglazova 2020). Nonetheless, under the impact of the World Englishes paradigm, the article points to blurring the concept of "external culture" - Russian bilinguals, speaking or writing in Russian English, use this variety for expressing their own culture; the same is true for other world Englishes that have branched from the prototypical British English model. Despite the polemical relations of the two research schools, which are close and yet different in some of their tenets, there is much in common in their semantic and pragmatic research of how varieties of English adapt and domesticate culturonyms, in particular binary words belonging to two languages and often associated with each other in translation. The paper discusses examples of binary polyonyms ("universal" culturonyms) whose meaning depends on the context of the situation and, therefore, is differently received in diverse cultures; binary analogues whose equivalent selection is based on scrutinizing the dictionary entry and on the knowledge of the cultural background, and binary interonyms that partly help translators and partly interfere with their work, being deceptive cognates differing in their referential or connotational meanings. The article concludes that the interpretation of culture-bound words in foreign-culture-oriented texts depends on various pragmatic and semantic processes and is grounded in a word semantic flexibility and its matter-of-course adaptation in a cultural and language environment.
\end{abstract}

Keywords: culture-bound word, translation correlation, equivalence, adequacy, intercultural communication, adaptation, semantics, pragmatics

\section{For citation:}

Kabakchi, Victor V. \& Zoya G. Proshina. 2021. Lexico-semantic relativity and versatility in translation and intercultural communication. Russian Journal of Linguistics 25 (1). 165-193. DOI: 10.22363/2687-0088-2021-25-1-165-193 


\title{
Лексико-семантическая относительность
}

\author{
и адаптивность в переводе \\ и межкультурной коммуникации
}

В.В. КАБАКЧИ ${ }^{1}$, 3.Г. ПРОШИНА ${ }^{2}$

${ }^{1}$ Российский государственный педагогический университет им. А.И. Герцена

Санкт-Петербург, Россия

${ }^{2}$ Московский государственный университет имени М.В. Ломоносова

Москва, Россия

\begin{abstract}
Аннотация
Цель работы - рассмотреть переводческие закономерности корреляции слов, представляющих денотаты, бытующие во многих культурах и составляющие своеобразие отдельных культур и языков. В фокусе внимания - русско-английские культуронимы. Рассматривается принцип функционального дуализма языка, утверждающий обращенность языка к внутренним и внешним культурам и разрабатываемый в достаточно новой лингвистической дисциплине под названием «интерлингвокультурология» (Кабакчи 1998, Кабакчи, Белоглазова 2020). Вместе с тем под давлением идей контактной вариантологии английского языка (World Englishes paradigm) отмечается размывание понятия «внешней культуры», поскольку русские билингвы, говорящие или пишущие на русском варианте английского языка, используют этот вариант для передачи своей собственной культуры; то же самое касается и всех других вариантов английского, отпочковавшихся от своей прототипической британской модели. Несмотря на полемический характер соотношения двух близких, но, тем не менее, различающихся школ, есть много общего в их исследовании семантико-прагматических процессов освоения вариантами английского языка культуронимов, и в частности бинаров, то есть межъязыковых пар, ассоциируемых друг с другом в процессе перевода. В работе рассматриваются примеры бинаров-полионимов, значение которых привязано к контексту ситуации, и потому они по-разному воспринимаются по отношению к разным культурам; бинаров-аналогов, выбор эквивалентов которых зависит от внимательного изучения не только словарных дефиниций, но и овладения соответствующим культурным фоном; бинаров-интеронимов, часть которых помогают переводчику, в то время как другая часть являются ложными когнатами, поскольку они отличаются либо своими референциальными, либо коннотативными значениями. В заключение делается вывод о том, что интерпретация культуронимов подвержена разным прагматическим и семантическим процессам и обусловлена семантической гибкостью слова и его неизбежной адаптацией в культурно-языковой среде.
\end{abstract}

Ключевые слова: культуроним, переводческая корреляция, эквивалентность, адекватность, межкультурное общение, адаптация, семантика, прагматика

\section{Для цитирования:}

Кабакчи В.В., Прошина 3.Г. Лексико-семантическая относительность и адаптивность в переводе и межкультурной коммуникации. Russian Journal of Linguistics. 2021. Т. 25. № 1. C. 165-193. DOI: 10.22363/2687-0088-2021-25-1-165-193

\section{1. Введение}

В последней четверти XX в. наступила эпоха «глобанглизации» (Кабакчи, Юзефович 2007: 115) с доминированием английского языка. 
В центре внимания многих лингвистов оказались многочисленные варианты английского языка в различных уголках земного шара, получившие казавшееся сначала аграмматичным название world Englishes (первое упоминание в научном дискурсе - в статье Б. Качру (Kachru 1980), впоследствии оно утвердилось в соответствующем имени журнала, выпускаемого издательством Wiley-Blackwell и ставшего рупором новой теоретической парадигмы, называемой в России контактной вариантологией английского языка (Прошина 2008, 2017).

Трампизм США середины второго десятилетия XXI в. резко изменил ситуацию в мире, который из монополярного превратился в многополярный, и сейчас уже пророческими кажутся слова, прозвучавшие на токийском симпозиуме в третьей четверти ХХ в.: «Возможно, в следующие два столетия самой большой проблемой человечества станет сохранение вариативности культур и даже оптимальная степень изоляции перед угрозой невероятного давления мировой “суперкультуры”, выстроенной на научном основании» 1 ("It may be that the greatest problem of the human race in the next two hundred years will be the preservation of variety of culture and even of the optimum degree of isolation, in the face of the enormous pressures of the science-based world 'superculture"') (Boulding 1976: i).

Контактная вариантология, как показало время, имеет много общего с возникшей в нашей стране теорией интерлингвокультурологии (Кабакчи 1998, 2011, Кабакчи, Белоглазова 2020), обе концепции оказались востребованными. Однако есть между двумя парадигмами и весомые отличия (Прошина 2018), придавшие полемичность данной статье.

Целью данной работы стало стремление показать некоторые закономерности сопоставительной лингвокультурологии, лексикологии и переводоведения в объединенных рамках двух вышеназванных парадигм, что имеет особую значимость для практики перевода и межкультурной коммуникации.

\section{2. Функциональный дуализм языка: его первичная и вторичная культурная ориентация}

Распадались империи, для народов мира стала ясна необходимость использовать английский язык (и другие ведущие языки международного общения) в приложении к своим культурам для выхода на более широкую аудиторию. Актуальной стала ориентация этих языков на иноязычную культуру. Самым востребованным оказалось использование в этой функции английского языка как языка глобального общения (Crystal 1997), или lingua franca (Seidlhofer 2011).

Распался и Советский Союз, ослабли позиции русского языка, о русской культуре стали говорить и писать на глобальном лингва франка, что вызвало интерес к теории и практике англоязычного описания русской культуры

\footnotetext{
1 Здесь и далее переводы З.Г. Прошиной.
} 
(Russian-Culture-Oriented English, RCOE), ставшего основным объектом изучения интерлингвокультурологии и привлекавшего внимание исследователей русского варианта английского языка в рамках контактной вариантологии (Proshina \& Eddy 2016).

Лингвисты прошлого гипертрофировали уникальность языка. Так, по мнению В. Гумбольдта, «...каждый язык описывает вокруг народа, которому он принадлежит, круг, откуда человеку дано выйти лишь постольку, поскольку он тут же вступает в круг другого языка» (Гумбольдт 1984: 80). Ему вторит и Л. Витгенштейн: «Тот факт, что мир есть мой мир, проявляется в том, что границы языка (единственного языка, который понимаю я) означают границы моего мира» (Витгенштейн 1958: 81).

Между тем, в условиях многоязычного мира ни один язык, тем более политически активного народа, не может замыкаться на своей («внутренней», internal), культуре, но вынужден обращаться и к иноязычным («внешним», external) (Кабакчи 1998) культурам земного сообщества. Иными словами, мы имеем дело с «функциональным дуализмом языка» (Кабакчи 2005), с его двусторонней культурной направленностью: в зависимости от коммуникативной ситуации язык переключается с мира внутренней культуры на зарубежный мир внешних культур. Естественно, исторически всем своим развитием язык ориентирован на свою, внутреннюю, культуру.

\section{3. Словарь и его культурная ориентация}

Окружающий нас мир - это миллионы разнообразных объектов, одушевленных и неодушевленных, связей между ними и процессов. Они закрепляются в языке, в первую очередь, благодаря словам. «Значений в некотором континууме выделяется столько, сколько подразделений в нем существенны для человеческой практики. И значения эти настолько дискретны, насколько существенна и отработана в опыте дискретизация соответствующего участка денотативной сферы» (Никитин 1996: 207).

В поле зрения образованного человека, по мнению лингвистов, находится лишь часть словарного запаса языка ${ }^{2}$, при этом отечественные ученые утверждают, что среднестатистический человек имеет в своем лексиконе порядка 50 тыс. слов (Панов 2007), а зарубежные исследователи настаивают на еще меньшей цифре: «...вряд ли большинство людей, говорящих на английском языке, знают более 20-30 000 слов - примерно такое количество слов доступно большинству людей на любом языке» (“...it is not likely that most English speakers know more than 20-30,000, or about the number of words available to most human beings in any language") (Haugen 1966: 22). Этот сравнительно незначительный набор наименований элементов окружающего нас

2 Второе издание Oxford English Dictionary (1989) содержит 291500 лемм (https://public.oed.com/history/oed-editions/ (дата обращения: 06.07.2020)), а вместе с ежеквартальными дополнениями в нем уже 616000 слов. 
мира фактически (судя по языковой практике) оказывается достаточным для его описания.

Слова делятся на классы, каждый из которых выполняет определенную коммуникативную функцию. Для наименования элементов окружающей действительности в первую очередь используется имя существительное. Описание культуры невозможно без использования наименований элементов культуры. Вместе с тем значительная часть словарного состава нейтральна по отношению к культурной ориентации текста. В первую очередь к таким словам следует отнести служебные части речи (предлоги, союзы, артикли). В эту группу также входят те знаменательные части речи, которые не являются наименованиями специфичных культурных элементов и могут в равной степени участвовать при описании самых различных культур народов мира местоимения, наречия, числительные, большая часть прилагательных, глаголов и значительная часть имен существительных. Это, например, английские слова back, large, they, nine, to dance, cold, happiness.

Наименования элементов культуры мы называем «культуронимами» (Кабакчи 1998), которые делим на полионимы и идиокультуронимы. К «полионимам» относятся имена существительные и субстантивные словосочетания, выступающие в качестве обозначения таких элементов окружающего нас мира, которые представлены во всех или в большей части существующих в настоящее время культурах народов мира (например, телевизор, жилье, мир). Это универсальные культуронимы, которые появляются в различных культурах в результате центростремительных процессов развития земной цивилизации.

Идиокультуронимы представляют собой специфические наименования элементов культур. В интерлингвокультурологии данный класс слов далее делится на идионимы - исходные, «свои», наименования специфических элементов внутренних культур и ксенонимы - иноязычные, «чужие» идиокультуронимы, переводные варианты идионимов. Идионимы - это результат первичной вербализации культурного континуума, в то время как ксенонимы - результат его вторичной вербализации. Сравним две группы культуронимов с привлечением русского и английского языка. I. Идионимы: (1) русский язык цуарь, казак, cmenь, cmapoвер; (2) английский язык lord, House of Commons, Church of England, pub. II. Ксенонимы: (1) русский язык лорд, палата общин, Англиканская церковь, паб; (2) английский язык tsar, Cossack, steppe, Old Believer.

Однако в контактной вариантологии, признающей факт дифференциации плюрицентрического английского языка на варианты, принадлежащие не британской (первичной), а своим культурам, это деление идиокультуронимов вызывает много вопросов, главный из которых следующий: как можно считать, что английский язык более поздних вариантов выражает не их родную, а первичную (британскую) культуру, если он вобрал в себя контактирующие элементы коренного населения, ставшие неотъемлемой частью вокабуляра данного варианта, но чуждого для британской культуры? Не является ли 
такое деление культуронимов проявлением «нейтив-спикеризма» (Holliday 2006)? Ведь сегодня английский язык принадлежит не только британцам и представляет собой не только национальные, но и региональные варианты. Для британцев американское слово cowboy, австралийское kangaroo не являются элементами их культуры и, соответственно, не могут считаться идионимами, в то время как для англоязычных американцев и англоязычных австралийцев это, конечно, элементы их родной (внутренней) культуры. Точно так и для англоязычных индийцев слова sari, masala chai, pandit и др. это слова их родной культуры и для многих индийцев - слова даже родного языка ${ }^{3}$, потому они не могут считаться ксенонимами для индийского варианта английского языка. Аналогично, те, кто используют английский язык как свой «функционально-родной вариант» (Kachru 1998, Smith 2008/2016), то есть приобретенный, но освоенный до высокой степени языковой компетентности, считают его вторичным средством выражения их родной культуры, но не «чужим», поэтому возникает сомнение в том, что для русского варианта английского языка слова tsar, Cossack, steppe, Old Believer являются «чужими» номинациями, или ксенонимами.

\section{4. Дилемма доступности и адекватности}

Даже если не делать деления идиокультуронимов на «своих» и «чужих», многие исследования подтверждают специфику использования языка в ориентации не только на свою, но и на культуру других стран: «Использование неродного языка в контекстах родной культуры для обозначения новых тем, характеров и ситуаций сродни переформулированию семантического и семиотического потенциала языка, что заставляет его выражать значение того, что не является частью его традиционного 'значения'» ('Using a non-native language in native contexts to portray new themes, characters, and situations is like redefining the semantic and semiotic potential of a language, making language mean something which is not part of its traditional 'meaning' ") (Kachru 1992: 316-317).

Основной проблемой англоязычного описания русской культуры оказалось достижение разумного компромисса точности текста и его доступности. Точность описания, как показали исследования, достигается (в том числе) путем непосредственного введения в текст транслитерированных русизмов (Кабакчи 1996, 1998, Кабакчи, Юзефович 2007). Переполнение текста иноязычного описания непонятными заимствованиями делает его труднодоступным для непосвященных: "Not Do svidania but Proshchai - this is a final parting never again shall I see these hills" (Pray 2019: 11). Сравните аналогичное

\footnotetext{
${ }^{3}$ Согласно данным переписи 2011 г., в Индии около 260,000 чел. считают английский своим первым языком (https://censusindia.gov.in/2011Census/Language-2011/Statement-1.pdf; дата обращения 03.07.2020), вторым языком его признают 83 миллиона индийцев (https://www.livemint.com/news/india/in-india-who-speaks-in-english-and-where-1557814101 428.html; дата обращения 03.07.2020).
} 
впечатление от русского текста, изобилующего английским заимствованиями в устаревшей и кажущейся сегодня искаженной форме:

За кофеем Александр Иванович [Герцен] читал «Теймс», делал свои замечания и сообщал нам разные новости. ... Во втором часу в столовой был приготовлен завтрак (lunch), который состоял из двух блюд: почти всегда из холодного мяса и еще чего-нибудь из остатков вчерашнего обеда. На столе стояли кружка pal al (должно быть, pale ale - светлого пива. - Авт.) и бутылка красного вина или хереса. Герцен очень любил pal al и пил его ежедневно (Романюк 2009: 135).

Конечно, можно минимизировать присутствие в тексте заимствований, но это снижает точность описания. Достаточно сравнить оригинальное предложение с его упрощенным вариантом:

The young Peter had a wet-nurse (kormilitsa), nurse (mama), and nanny (niania) (Hughes 1998: 195). => The young Peter had a wet-nurse, nurse, and nanny.

При опущении русских реалий текст стал предельно простым, потеряв, однако, свою точность. В первом случае специалист или, по крайней мере, любознательный читатель, может восстановить оригинальное написание слов и перейти к русскоязычным источникам. Упрощенный вариант дает лишь приблизительное представление об описываемой культуре.

В последнем примере мы убедились, что упрощение текста достигается ценою значительной потери точности. По словам В.П. Беркова, «...в целом при переводе всегда происходит потеря информации, и поэтому, сравнивая два разных эквивалента для одного и того же слова другого языка, мы должны определенным образом оценивать степень потери информации в каждом из них» (Берков 1977: 49).

Анализ текстов показывает, что в подавляющем большинстве случаев они заполнены «полионимической» лексикой, знакомой читателю. Достаточно взглянуть на следующий отрывок оригинального текста:

Dr. Pnin nimbly walked into the passage, voiced a query, received a quiet answer, and returned with his son Timofei, a thirteen-year-old gimnazist (classical school pupil) in his gimnazichesky uniform - black blouse, black pants, shiny black belt (I attended a more liberal school where we wore what we liked).

Do I really remember his crew cut, his puffy pale face, his red ears? Yes, distinctly. I even remember the way he imperceptibly removed his shoulder from under the proud paternal hand, while the proud paternal voice was saying: 'This boy has just got a Five $\left(\mathrm{A}^{+}\right)$in the Algebra examination' (Nabokov 1990: 130).

Налицо целый ряд реалий: имя героя романа (Timofei, Pnin); русизм gimnazist параллельно поясняется, а в случае русизма gimnazichesky автор полагает, что читатель поймет это прилагательное, особенно с учетом 
существования слова 'gymnasium', у которого уже появляется и новое значение: (1) a room or building equipped for gymnastics; (2) a school in Germany or Scandinavia that prepares pupils for university entrance (OEED). Однако подавляющая часть слов знакомы англоязычному читателю и воспринимаются в хорошо известном им значении (black blouse, black pants, shiny black belt, a liberal school). Следует также обратить внимание на пояснение оценки «5» с помощью американского аналога: a Five $(\mathrm{A}+)$.

Полионимическая лексика, которая является действием центростремительных процессов развития земной цивилизации, характеризуется гибкостью и способностью адаптироваться в соответствии с коммуникативной ситуацией. «...Нельзя указать с полной определенностью, сколько значений у слова и какие это значения, так, чтобы наперед задать все возможные речевые актуализации слова», - справедливо утверждал М. В. Никитин (Никитин 1983: 23-24). В данном случае лингвист лишь поддерживает традиционную точку зрения: «Случаи полного совпадения лексических единиц разных языков во всем объеме их референциального значения относительно редки» (Бархударов 1975: 75). В этом случае зарубежные переводоведы говорят о дирекциональной (directional) эквивалентности, противопоставленной естественной (natural) эквивалентности в том, что первая представляет собой асимметричные и контекстуально зависимые отношения в исходном и переводном текстах и не всегда допускает эквивалентную обратимость перевода в другую сторону, в то время как вторая существует еще до начала процесса перевода и имеет достаточно жесткий эквивалент (Рут 2010: 7, 26). Впрочем, как отмечает Энтони Пим, естественная эквивалентность - скорее идеальное соотношение исходного и переводного слова и редко встречается в реальной переводческой ситуации.

\section{5. Принцип языковой экономии и бинары как лексические межъязыковые пары}

Межкультурная коммуникация происходит в условиях билингвизма или даже мультилингвизма, а это во многих отношениях определяется фактором экономии языковых средств, на что указывал уже Г. Пауль: «В целом для языковой деятельности характерна определенная тенденция к бережливости» (Пауль 1960: 372). По словам Андре Мартине, в ходе общения люди предпочитают путь наименьшего сопротивления (Мартине 1963: 532). А. Мартине описал экономию речевых усилий, которую О.С. Ахманова (1966: 152) назвала лингвистическим законом на фонетическом уровне, но в действительности этот закон проявляется на всех уровнях языковой структуры, в том числе лексико-семантическом, тем более в речевой деятельности и, конечно, в переводе.

Описание иноязычной культуры - это поиск оптимального варианта перевода русского культуронима. При этом осуществляется сопоставление культуронимов на межъязыковом уровне. Языковая практика отбирает 
наиболее популярные (хотя далеко не всегда адекватные) варианты перевода, а лексикографы закрепляют это в двуязычных словарях в виде пар переводческого соответствия, которые мы называем «бинарами» («бинарные лексические межъязыковые пары», bilingual cultural substitutes) (Кабакчи, Белоглазова 2020: 26), т.е. межъязыковые пары лексических единии, которые регулярно в ходе межкультурных контактов в процессе перевода механически ассоциируются друг с другом. Однако словарные соответствия никоим образом нельзя рассматривать как межъязыковую эквивалентность.

В практике межкультурных контактов бинары могут быть как в достаточной степени адекватными (назовем их «рабочими») вариантами перевода культуронимов, так и теми подводными камнями (типа «ложных друзей переводчика»), на которые так часто натыкается специалист. По мнению Г. Пауля: «Когда значение какого-либо иностранного слова совпадает со значением слова их родного языка, но лишь частично, мы часто склонны приписывать иностранному слову полный объем значения, которым обладает родное слово. Как известно, эта ошибка является одной из самых распространенных при упражнениях в переводе» (Пауль 1960: 470-471).

Характеризуя поиск переводческих соответствий, составляющий «семантическую инженерию перевода» (Бурак 2010: 141), А.Л. Бурак выделил несколько уровней переводных коррелятов: 1) близкие соответствия (эквиваленты) (close approximations): монтировка - a tire iron; 2) практические соответствия (adequate approximation, near equivalents): кинуть кого-mo - to stiff sb; 3) функционально-коммуникативные аналоги/соответствия (functionalcommunicative analogues): aвось - blind trust in sheer luck / divine providence / faith in serendipity; 4) толкования, или описания-дефиниции (translation by paraphrase (interpretations or translation through definitions): голубой огонёкa popular New Year's Eve TV show; 5) переводы-кальки (loan translations, calques): новые pyсcкие - new Russians; 6) переводы-транскрипции / транслитерации: Дума - the Duma, крылиа - krisha; 7) беспереводные заимствования, иначе называемые трансплантации: VISA, Windows (Бурак 2010: 141-142).

Существуют различные типы бинаров, которые, в зависимости от конкретной ситуации общения, в большей или меньшей степени влияют на восприятие текста описания иноязычной культуры. Эти бинары могут быть двух типов: гетерогенные, т.е. не имеющие общей этимологии (улица / street) и гомогенные, восходящие к общему иноязычному источнику (армия / army).

\section{6. Гетерогенные бинары}

\section{1. Гетерогенные бинары-полионимы с близкими значениями}

Рассмотрим предложение: It appears that he climbed into a window over in the house and got upstairs, but was discovered before he stole anything.

С точки зрения культурной ориентации это предложение представляется космополитичным, поскольку ничто в нем не указывает на какую-либо 
конкретную культуру. Культуронимы 'window' и 'house' можно рассматривать как полионимы. Вместе с тем очевидно, что эти культуронимы будут изменять свое значение, оказавшись в конкретном культурно ориентированном контексте. Слово 'window' обозначает элемент стены дома, который имеет разную форму и разные размеры в зависимости от страны и климата. Слово 'house' также обозначает разные виды зданий, отличающихся по форме, высотности, функциям - оно может относиться как к жилым помещениям, так и официальным и функциональным сооружениям. Существительное 'upstairs' в ассоциации с домом может относиться ко второму этажу типичного американского дома, где обычно расположены спальни, тогда встает вопрос: что вор делал в спальне? Это же слово может относиться к чердаку обычного русского деревенского дома, что придает еще больше интриги описываемой ситуации: на чердаке хранились какие-то сокровища? Для адекватного восприятия текста необходимо знание культуры и исторической эпохи. В зависимости от ситуации общения полионимы 'window', 'house и 'upstairs' наполняются различным содержанием, адаптируя его в ориентации на эту ситуацию.

Теперь несколько изменим это предложение и посмотрим, как оно звучит в оригинале: It appears that he climbed into a window over in Churin's house and got upstairs, but was discovered before he stole anything (Pray 2019: 45). Это строчка из собрания писем американки Элеоноры Прэй, долгие годы прожившей в дореволюционном Владивостоке. Введение в предложения собственного имени Churin сразу многое скажет человеку, знакомому с историей Дальнего Востока: компания Чурина была известна своими большими торговыми домами не только во Владивостоке, Хабаровске и других городах Восточной Сибири и Дальнего Востока, но и в Китае (одним из символов Харбина до настоящего времени является Qiulin lieba - Чуринский хлеб ${ }^{4}$ ). Поскольку действие разворачивается во Владивостоке, то становится ясно, что через окно вор проник в универмаг, как мы бы назвали его сейчас, и поднялся на верхний этаж, где и был пойман. Следовательно, только контекст ситуации наполняет конкретным содержанием полионимы, которые, подобно семантическим хамелеонам, приспосабливаются к ситуации, реализуя свое лексическое значение.

Таким образом, мы видим, что универсальный характер языка, позволяющий нам обращаться к любой тематике, основан на необычайной гибкости семантики лексических единиц, которыми, в принципе, в пределах довольно ограниченного запаса словарного состава располагает обычный человек. Однако именно эта гибкость и таит в себе опасность искаженного восприятия исходной информации.

${ }^{4}$ См., например, статью в газете “China Daily”. URL: https://www.chinadaily.com.cn/ food/2015-03/26/content_19917551.htm (дата обращения: 07.02.2020). 


\section{2. Гетерогенные бинары-аналоги с выборочными эквивалентами}

Переводческая практика сводит в межъязыковые пары далеко не равнозначные культуронимы и закрепляет это двуязычными словарями.

\section{(1) Например: деревня/village}

Популярная сказка П.П. Ершова «Конёк-Горбунок» открывается в хорошем англоязычном переводе словами: "Past the woods and mountains steep, / Past the rolling waters deep, / You will find a hamlet pleasant / Where once dwelt an aged peasant" (Yershov 1988: URL). В оригинале «Жил старик в одном селе». «Село» - это большой населенный пункт, почему же переводчик предпочел не обычное словарное соответствие, 'village', а слово 'hamlet'? Обратимся к словарям и непосредственно к практике:

hamlet: a very small village; e.g.: Both lived in Coahoma, a hamlet of about 1,200 residents 10 miles to the east of Big Spring [LDCE].

Как видим, масштабы определения величины населенного пункта не российские. С одной стороны, hamlet - это, судя по словарю, очень маленькая деревня (a very small village), но, с другой стороны, если верить примеру, в ней может проживать около 1200 жителей. Другие британские словари (OALD, CIDE) добавляют: usually without a church - обычно без церкви.

Обратимся теперь к слову village:

village: "a group of houses and associated buildings, larger than a hamlet and smaller than a town, esp. in a rural area" (OEED).

Wikipedia даже приводит примерные цифры населения, которые уж никак не соответствуют нашим представлениям о российской деревне: “А village is a clustered human settlement or community, larger than a hamlet but smaller than a town, with a population ranging from a few hundred to a few thousand" (Wikipedia: village). T.e. 'village' для английского языка - это маленький, но все-таки город. Показательно, что Хедрик Смит в своей книге о брежневском Советском Союзе в приложении к нашей деревне использует именно слово 'hamlet': The snowbound hamlets with their weatherbeaten, smoking peasant izbas, floated past like unconnected islands, seemingly uninhabited in the sea of snow (Smith 1976: 409).

\section{(2) обед/dinner}

Значительные искажения в восприятии англоязычного описания русской культуры вносит эта пара фактических аналогов, а не эквивалентов ${ }^{5}$. В английском языке слово 'dinner', как и 'to dine”, описывает прием пищи нередко вне дома и ближе к вечеру: 'the main meal of the day, eaten in the middle of the day or the evening' (LDCE). Иностранцы, описывая Россию, обычно это подчеркивают: Most people had gone home: the Russians normally dined at two

5 Здесь мы приближаемся к пониманию терминов 'эквивалент' и 'аналог' в рецкеровском толковании постоянного равнозначного соответствия и вариантного соответствия (Рецкер 2004). 
but it was not unusual for Bobrov to be in his office this late, since he often dined in the fashionable English quarters, where they liked to eat at five. (Rutherford 1992: 534). Cf.: The delegation has decided to have dinner at seven o'clock American style ... (Wilson 1961: 55).

\section{(3) стакан/glass}

В случае данной пары бинаров мы имеем дело с видо-родовыми отношениями. Стакан - это стеклянный сосуд без ручки, близкий по форме к цилиндру или усеченному конусу; конкретный сосуд для питья без привязки к какой-либо индивидуальной жидкости. Дизайн легендарного граненого стакана советского образца часто приписывают советскому скульптору Вере Игнатьевне Мухиной.

Между тем 'a glass' - это, согласно OEED, 'a drinking vessel', причем назначение и форма этого «сосуда для питья» в отсутствие уточняющего определения весьма неопределенны. Форма сосуда меняется в зависимости от напитка, для которого он предназначается, и узнается по соответствующему словосочетанию: a drinking vessel made of glass: a beer, brandy, sherry, whisky, etc. glass, e.g., 'a wineglass' [OALD]. В случае пива словарь CIDE поясняет: "If you are served beer in a straight glass, you are given it in a glass with no handle.” Иными словами, 'glass' в приложении к русской традиции может быть «бокал», «рюмка», «стопка», «стакан» ...

Поскольку на Западе насаждается стереотип русского алкоголизма, в текстах часто встречается сочетание “a glass of vodka". При этом объем сосуда представляется очень большим: His eye lighted on the glass of vodka from the night before (Lear 1986: 124).

Искажение восприятия описания русской культуры отчетливо видно в следующем примере. Журналист петербургской газеты экспатриантов рассматривает меню, в котором указано, что вместе с супом подается "a glass of vodka", и это приводит его в ужас. Между тем, сам журналист, увидев то, что принес официант, описывает это фразой "a shot of vodka": [Our soups] came with a shot of vodka (or as the English version of the menu frighteningly had it, a glass) (SPbTimes 22.09.2000).

Таких примеров в русско-английских словарях великое множество, и их использование неизбежно приводит к неверному представлению русской культуры. Вот лишь несколько примеров таких неадекватных замен в тексте романа Fathers and Sons: губерния province; именье estate; лампада lamp; изба $\sim$ cottage (Turgenev 1965).

Подобные неточности в переводе не могли остаться незамеченными. В частности, на несуразность приравнивания английского слова «porridge» к русскому идиониму «каша» обратил внимание Кевин Маккой, который назвал это явление «синдромом kasha» (McCaughey 2005): 
“...kasha is translated in virtually every textbook as 'porridge'. So porridge is the word used by today's English speakers when referring to a particular Russian dish that has little to do with the English/Scottish breakfast food". 6 (McCaughey 2005: 457)

Прекрасный знаток русской кухни Л. Чемберлен уже писала об этом значительно раньше:

"[The English word 'porridge'] is no good for translating kasha. It deters those who do not share my early morning tastes and suggests sticky mush, whereas kasha covers almost all ways of cooking all grains in water, milk, stock and cream to a variety of consistencies ranging from dry (like rice) to set (like Italian polenta) to a thick purée". (Chamberlain 1983: 174)

\section{7. Гомогенные бинары-интеронимы}

Межъязыковые лексико-семантические бинары, близкие не только по значению, но и по форме, естественным образом ассоциируются друг с другом, и на первый взгляд представляется, что именно они в первую очередь объединяются в бинары. Они имеют общее происхождение и существуют во многих языках, а потому называются интернационализмами. Согласно авторитетному «Лингвистическому энциклопедическому словарю» (ЛЭС), интернационализмы - это «слова, совпадающие по своей внешней форме (с учетом закономерных соответствий звуков и графических единиц в конкретных языках), с полно или частично совпадающим смыслом, выражающие понятия международного характера из области науки и техники, политики, культуры, искусства и функционирующие в разных, прежде всего неродственных (не менее чем в трех) языках. ... Удельный вес интернационализмов в ряде языков достаточно велик (например в активном словаре русского, английского, немецкого, французского языков их более $10 \%$ (Бельчиков 1990: 197).

Русский язык удивительно толерантен к иноязычным заимствованиям из западноевропейских языков и накопил в своем арсенале их значительное количество. В последние десятилетия многие слова, попадающие в русский язык, приходят из английского - например, словарь англицизмов А.И. Дьякова (2014) включает около 20000 слов, большая часть из которых представляет собой слова интернационального хождения. Через английский язык в русский попало некоторое количество слов и восточноазиатского происхождения - такой путь заимствования называется опосредованным, а сами заимствования - опосредованными заимствованиями (Прошина 2020). Ряд таких слов имеет дискуссионную двойную форму, поскольку заимствование происходило письменным и устным путем: суси (устный путь заимствования) / суши (письменный путь, опосредованный английским языком - sushi); сасими/сашими; ср. тж. устаревшее гэйся - современное гейиа.

${ }^{6}$ В трехтомном НБРАС под ред. П.Н. Макурова, М.С. Мюллера и В.Ю.Петрова: каша kasha (dish of cooked grain or oats); porridge; (cooked) cereal; pap, gruel. 
Интернационализмы русского происхождения есть и в английском языке, собственно благодаря глобальному характеру которого слова русского языка нередко распространяются и закрепляются в других языках - например, интеллигенция/intelligentsia, mундpa/tundra, cmenь/steppe, водка/vodka.

Вместе с тем термин «интернационализм» имеет настолько широкое применение как термин социально-политический, что использовать его и как термин лингвистический для обозначения лексического типа слова представляется нецелесообразным. Поэтому мы предпочитаем воспользоваться термином, который предложен Свадостом: «интероним» (Свадост 1968: 48).

Видимое сходство интеронимов далеко не всегда гарантирует их межъязыковую эквивалентность. Лингвистам хорошо известно, что иноязычное слово, попав в новый язык, начинает подвергаться ассимиляции, приобретает новые значения.

Следует выделить несколько типов бинаров-интеронимов.

\section{Близкие интеронимы, типа университеm/university}

Это «классические» интеронимы, имеющие общее происхождение и совпадающие в своих основных значениях. Они, действительно, существенно помогают в межкультурном общении. Примерами таких интеронимов являются армия, глобализация, демаркаиия, дискриминация, идеология, кризис, модернизаџия, раџионализачия, револючия, рецессия, сочиалистический, функция, экскаватор, эскалатор, эскалация и многие другие.

В культурах с латинским алфавитом интеронимы могут иметь орфографические и произносительные различия, сравните: армия - army [англ.] armée [фр.] - Armee [нем.]; фотография - photography [англ.] - photographie [фр.] - fotografia [исп.] - Photographie [нем.].

Через латинизацию восточных слов в западноевропейских языках стали появляться также интеронимы китайского, японского и корейского происхождения: feng shui (англ., фр.) - Feng Shui (нем.) - фэн-шуй; karate - karaté (фр.) - Karate (нем.) - каратэ, kimchi (англ., фр.) - Kimchi (нем.) - кимчи. Однако некоторые из них, трансформировав значение в русском дискурсе, проявляют новое значение и в английском, как это, например, произошло со словом кимоно: в русском бытовом дискурсе оно стало обозначать «свободный халат с цельнокроенным рукавом»: “Aunt Galya appeared in my doorway almost every night, holding her faded silk robe over her large breasts. Her robe used to be a kimono, but she had holes on one side and sewn buttons on the other" (Vapnyar 2003: 128). "I'd never seen this pot before. Aunt Galya must have borrowed it from a neighbor, along with the green apron that was tied over her "kimono"' (р. 133). Попав в иноязычный дискурс, слово переориентировало свое значение с экзотического на бытовое, использовав отдаленное сходство объекта с формой своего первичного денотата.

\section{Идеологические интеронимы типа демократия/democracy}

Известно, что именно вокруг интеронимов типа демократия/democracy, либерал/liberal, национальный/national, etc. ведутся самые горячие споры, 
поскольку эти слова неоднозначно понимаются сторонниками различных идеологий и тем самым приобретают разные коннотации (Кабакчи 1990, Едличко 2009): e.g., Demokratizatsiya - another troublesome word because it does not mean the same thing as its English equivalent - democratization (Canadian Tribune 29.02.1988). Неслучайно подобные интеронимы нередко берут в кавычки, тем самым давая понять читателю, что автор дистанцируется от толкования данного слова в трактовке оппонентов: е.g., After 1957 the terms "revisionism" and "dogmatism" became an integral part of Communist discourse. They were applied in a variety of meanings (Encyclopedia Britannica 2001). Странная эта штука - “Западная демократия" и борьба за человеческие права... (Агни 2011: URL).

\section{Локалоиды типа (такси) taksi/taxi}

Локалоидами называются заимствованные слова, вернувшиеся в исходный язык в написании, отражающем произношение принявшего их языка (Кабакчи 1998: 63). Такого рода интеронимы отличаются своей орфографией, поскольку коррелируют в языках с разными системами письма: бизнес biznes - business.

Локалоид может облегчать запоминание иностранного слова, а значит и сам межкультурный контакт: You will be greeted by eager gypsy cab drivers shouting “Taksi! Taksi!” (Fodor 1999: 109). К такого типа интеронимам прибегают в официальных документах для точности обратного перевода и понимания в исходной культуре, например при передаче адреса, станции и т.д.: Lomonosovskiy Prospekt, Metro Universitet.

Локалоиды могут указывать на своеобразие значения этого слова в иноязычной культуре: The country was flooded with western culture, turning Russians into "biznesmen” overnight (Guardian 07 Feb 2003). К локалоиду порой прибегают из идеологических соображений, намекая на то, что похожее по форме слово фактически имеет совсем другое значение: Now the crime Lenin called speculation was known as biznes... (Meier 2004: 66).

Локалоиды охотно используют западные русологи (бывшие «кремлинологи»), демонстрируя знание профессионального жаргона. В следующем предложении примером является русизм “apparat”, даже не выделяемый кавычками: They had been Party members in high standing. Rimma had worked in the local apparat (Meier 2004: 375).

Во всех подобных случаях в распоряжении неподготовленного читателя имеется лишь общий интернациональный компонент, что оставляет значительное поле для свободных интерпретаций. Локалоид адаптируется в соответствии с культурно-образовательным фондом адресата.

\section{Интеронимы - «ложные друзья» типа магазин/magazine}

Нельзя, конечно, не упомянуть и так называемых «ложных друзей переводчика». Повышенный интерес к этому переводческому явлению наблюдался в 1960-х гг,, и в СССР был связан в первую очередь с работами В.В. Акуленко. В частности, можно назвать Англо-русский и русско- 
английский словарь “ложных друзей переводчика”, созданный под его руководством в 1969 г., куда вошла и его статья о «ложных друзьях» (Акуленко 1969). К ложным когнатам (deceptive cognates) (Newmark 1988), как иногда называют «ложных друзей переводчика», вернулись в самое последнее время в связи с небывалым масштабом изучения английского языка в качестве второго или иностранного, что неизбежно сталкивает изучающих язык и с проблемой «ложных друзей». Эти слова уже стали включать в учебные словари, например, Cambridge International Dictionary of English.

По семантической и формальной связи в двух языках ложные друзья переводчиков делят на межъязыковые синонимы, межъязыковые омонимы и межъязыковые паронимы (Прошина 2019: 178). Межъязыковые синонимы могут иметь одну (или более) общую семему в семантических структурах своих слов, но при этом расходиться в других своих значениях - например, амбиция/ambition: английское ambition имеет значение 'determination to be successful, rich, powerful, etc.; a desire to achieve something' (LDCE); в то время как русское слово амбиция еще недавно определялось словарем Ожегова как слово с исключительно отрицательной коннотацией «1) Обостренное самолюбие, а также спесивость, чванство; 2) Обычно мн. Претензии, притязания на что-либо» (ТСРЯ 2000). Однако в последнее время в русском языке у слова амбиция стало появляться значение, близкое английскому ambition - например, Википедия дает дефиницию слова «честолюбие» через синонимичное «амбиция»:

Под честолюбием (или амбициями) понимается закрепленное в характере стремление человека достичь успехов в соответствии с личными целями в таких сферах жизни, как личная производительность, успех, признание, влияние, лидерство, знания или власть (Википедия 2020: Честолюбие).

Это же значение русского слова закрепляется и как психологический термин: «Амбиции - это степень человеческого честолюбия, его устремленность на достижение целей, желание получать внешние знаки почета и уважения, достоинство и гордость индивидуума. Другими словами, это степень размаха субъекта на достижение жизненных благ, профессиональной и межличностной реализации» (Психология и психиатрия 2020). Таким образом, одно из значений двух слов сегодня совпадает, а два других - нет.

Непринятие во внимание различий в семантических структурах коррелирующих лексем двух языков приводит зачастую к легкому опознанию того, что человек говорит/пишет на неродном для себя языке - в контактной вариантологии считается, что в данном случае проявляется мезолектное использование варианта языка (Прошина 2017). Например, для русских, пользующихся английским языком, достаточно частотно употребление слов science, scientific как эквивалентов словам наука, научный, даже когда речь идет о гуманитарных науках, в то время как эти слова должны соотноситься с естественными науками (Виссон 2003: 167) - «scientific-practical conference 
in language issues" и т.п. Соответственно, у наших зарубежных коллег недоумение вызывают наши научные степени Candidate/Doctor of Science, когда речь идет о гуманитариях.

Иногда выбор интеронима затрудняется узусом, закрепившим разные эквиваленты в различных речевых сообществах. Например, коллокации педагогический университет/институт вполне мог бы соответствовать английский эквивалент pedagogical university/institute, поскольку слово "pedagogical" имеет значение "related to the methods and theory of teaching" (CED). Именно так обычно переводят наименования соответствующих вузов России. Однако иногда названия российских педуниверситетов встречаются в переводе как teacher training university, по аналогии с некоторыми зарубежными учреждениями и программами: He was teaching psychology in Moscow State Teacher Training University... (Fleer \& Oers 2018: хxi). В Китае же стабильным эквивалентом для англоязычного обозначения педуниверситета стало наименование normal university - еще один «ложный друг переводчика»: например, "With the rapid changes in Chinese society, young people are under greater pressure than ever before," said Lin Guirui, director of the psychological counseling center at Beijing's Capital Normal University (Stevenson et al. 2005: 289).

Вторая группа - межъязыковые омонимы - как и омонимы в рамках одного языка, это слова, близкие по форме, но совсем не имеющие общих значений - например, англ. profane / рус. профан, где profane характеризуется следующими значениями: “adj 1) showing a lack of respect for God or holy things; 2) related to ordinary life, not religion or holy things" (LDCE), т.e. 1) богохульский и 2) мирской. Русское существительное профан - значит «человек, совершенно не сведущий в какой-либо области» (ТСРЯ). На современном этапе значения полностью расходятся.

Третья группа имеет несколько расходящиеся формы и отличающиеся значения похожих слов в двух языках - это межъязыковые паронимы: economical/экономический и, наоборот, есопотіс/экономичный. Слово economical значит "using money, time, goods etc carefully and without wasting any” (LDCE), а потому является эквивалентом русского слова экономичный, в то время как есопотіс означает "relating to trade, industry, and the management of money - economy” (LDCE), т.е. его переводным эквивалентом должно быть слово экономический, т.е. «имеющий отношение к производству, торговле, денежной сфере и т.п.» (ТСРЯ). Как известно из практики изучения языка, межъязыковые паронимы представляют одну из самых сложных проблем перевода.

Жертвами подобных «ложных друзей» нередко становятся западные русисты, не понимающие тонких различий между подобными бинарами, например, анекдот/anecdote ${ }^{7}$. If a Russian asks you whether you know any

${ }^{7}$ В английском языке сохранилось то значение слова «анекдот», которое присутствовало в русском языке в первой половине XIX в. Так, история о трех картах в «Пиковой даме» Пушкина рассматривается как «анекдот». В этом же значении мы встречаем это слово и у Достоевского. 
anecdotes, what they really want to know is whether you know any Russian anecdotes (SPbTimes 21.11.2013).

Между тем те, кто хорошо знакомы с русским языком и его культурой, не попадают в ловушку. Ср.: Nikita Khrushchev and Leonid Brezhnev were the butt of many popular jokes - referred to by Russians as anekdoty (SPbTimes 24.03.2000). Как видим, в данном случае автор правильно переводит русский идионим словом joke, а локалоид anekdoty приводит лишь для объяснения, что в России в таком значении используют знакомое читателю слово "anecdote".

\section{8. Адаптация значения слова}

Билингвизм ситуации общения, давление принципа языковой экономии, требующий установления двуязычной симметрии, вынуждают автора приписывать интеронимам то, что в английском языке для них нехарактерно, считать, что иностранное слово имеет полный объем значения, которым обладает родное слово, если оно хотя бы частично совпадает по значению с иностранным.

Так, английское слово academic (n/adj) указывает на человека или объект из академического мира высшего образования:

academic $n$ (1587) a teacher in a college or university; adj relating to education, especially of college or university level [LDCE].

Поэтому в приведенном ниже примере речь идет не об академике, а о политике Борисе Березовском, который из преподавателя превратился в олигарха: He was a fast-talking academic turned tycoon (Jack 2005: vii).

Вместе с тем в дискурсе о русской культуре слово вынуждено модифицировать свое значение, чему, возможно, способствует уже существующая коллокация 'academic theatre' с несколько иным значением в британском английском - 'студенческий театр'. В английском языке, ориентированном на русскую культуру, слово 'academic' стало означать 'in reference to artistic companies an honorary title'. Говоря о российском театре, например, американский журналист прямо указывает, что театру присвоили звание академического: Today it is an Academic Theater with 82 actors and a staff of 250-300 (Davidow 1977: 85).

В следующем примере это уже чисто профессиональный жаргон «русолога-кремлинолога», благодаря которому семантика слова «арparatus» адаптируется до значения советского термина «(партийный) аппарат»: Lukyanov's low profile within the state apparatus has allowed the Kremlin to discretely test the reaction ... (SPbTimes 03.07.2014).

Правда, в последние десятилетия советской власти английское слово фактически приобрело второе значение, ср.:

apparatus - (1) [uncountable] the set of tools and machines that you use for a particular scientific, medical, or technical purpose; SYN equipment; (2) [countable] the way in which a lot of people are organized to work together to do a job or control 
a company or country [LDCE]. Например, The national administrative apparatus must not, however, be considered solely as an agent of change (Laszio \& Kurtzman 1981: 70).

В следующем примере английское слово deficit, которое обычно используется исключительно как финансовый термин ("the difference between the amount of something that you have and the higher amount that you need" LDCE), под влиянием профессионального языка кремлинологов приобретает советское значение "shortage of goods": ...the late Soviet period was a time of deficit... (Kelly 2016: 09).

Так проявляется не только семантическая, но и, в первую очередь, культурная (прагматическая) адаптация текста, речи, а затем и языка к реальности - изучение подобного рода тенденций представляет собой один из новых трендов многих наук, в том числе переводоведения (Sdobnikov 2019). Сегодня это актуально не только для английского языка в его приложении к русской и другим культурам. Процессы, которые мы описали в данной статье, характерны для всех плюрицентричных языков: немецкого, испанского, французского и даже русского ${ }^{8}$.

\section{9. Факторы, влияющие на восприятие текста}

Поскольку, как было показано выше, культурная переориентация словарного состава связана со значительным варьированием восприятия текста, описывающего иноязычную культуру, и индивидуальной адаптацией семантики словарных единиц, возникает необходимость оценки адекватности восприятия такого текста. К факторам, определяющим эту адекватность, следует отнести следующее:

(1) знакомство читателя с описываемой культурой;

(2) общую эрудицию читателя;

(3) стереотип описываемой культуры, поддерживаемый официальными западными СМИ.

Все эти факторы влияют на смысловую интерпретацию слова и текста, которая рассматривается «не только в терминах трансформации языковых значений и концептуальных структур, но и более широко - как фактор формирования картины мира членов языкового коллектива» (Вишнякова 2018: 17).

Авторы западных текстов на английском языке, ориентированном на русскую культуру, своими комментариями определяют содержание идеологических интеронимов. В частности, в приведенном ниже примере это касается советского «Блокнота агитатора». Советизм «агитатор» для противников советской идеологии вообще был бранным словом: The Agitator's Notebook, whose title bespoke its political engaged role, started to celebrate the local past (Kelly 2014: 05).

${ }^{8}$ Вопрос о вариантности русского языка остается очень дискуссионным и требует особого внимания со стороны социолингвистов - см. статью «Национальные варианты русского языка» [ССЛТ 2006: 146]. 
Сразу отметим, что знание русской культуры в англоязычном мире весьма низкое. Наиболее значительное влияние оказывает негативный стереотип русской культуры, культивируемый средствами массовой информации, в соответствии с которым Россия - это варварская и агрессивная азиатская страна.

Попробуем подойти к текстам с учетом этих факторов. В приведенном ниже отрывке журналист США Хендрик Смит ${ }^{9}$ описывает свое пребывание в Якутии в 1970-х гг.:

\section{H. Smith in Yakutia}

It was a greedy, confident Siberian wintriness, devouring the hardy folk who labored along the sidewalks and chasing indoors those whose energies it had already eaten away. The day before, in one café, I had seen people banging through the door steadily, taking refuge over piping hot tea and lingering as long as possible in the stale communal warmth. I watched one worker chuga-lug a half-tumbler of brandy like a dose of antifreeze before having another go at the elements. Outside, people had surrendered any semblance of fashion to the all-consuming struggle to keep warm (Smith 1976: 400-401).

Определяющим фактором восприятия западным читателем этого отрывка будет негативный стереотип русской, тем более, советской, культуры, в частности штамп, сложившийся в отношении слова «Сибирь» ${ }^{10}$. Вот данные авторитетного словаря OED:

Siberia: Used as a type of a cold, inhospitable place, or a place of exile, banishment, or imprisonment. Also fig. (OED2 Online 2013: Siberia 1841).

Это значение постоянно обыгрывается в западных текстах и фильмах. Например, в популярном фильме Scent of a Woman отставной армейский офицер (Al Рacino), заказывая столик в ресторане, предупреждает: “And I don't mean Siberia."

А вот еще один пример из статьи Оксфордского словаря: In 1830 Andrew Jackson [ordered] that all the Indian tribes be removed to the west of the Mississippi, to the 'Siberia' of the Far West. (Listener (1972) 21 Dec. 857/3; цит. по: OED2 Online 2013: Siberia n.).

Этот стереотип накладывает свой отпечаток на восприятие читателем всего, что пишется о России. В тексте Х. Смита полионим «реорle» слишком широк по значению, чтобы понять его однозначно и беспристрастно в приложении к России; восприятие культуронима 'hardy folk', так же, как и в случае 'worker' и ряда других культуронимов, будет сильно зависеть от культурного

${ }^{9}$ Хедрик Смит (род. 9 июля 1933) был корреспондентом и редактором газеты The New York Times, с 1971 по 1974 гг. возглавлял московское бюро этой газеты. Именно тогда он написал свою известную работу The Russia о Советском Союзе брежневской эпохи. Это произведение стало учебником для сотен советологов и побило рекорды продаж, став непревзойденным американским бестселлером.

10 Об этноцентричной стереотипизации в дефинициях явлений русской культуры в учебных словарях английского языка см. статью (Ловцевич, Соколов 2020). 
кругозора читателя и того влияния, которое на него оказывает стереотип русской культуры.

Аналогичная ситуация и в случае культуронимов 'sidewalk' и 'café'. Обобщенно схематизированное представление о них, зафиксированное в словарях, таково:

sidewalk: a hard surface or path at the side of a street for people to walk on (LDCE);

café: a small restaurant where you can buy drinks and simple meals (LDCE).

Возникающая в представлении читателя картина также зависит от его эрудиции с поправкой на стереотип русской культуры. Режиссеру, которому бы понадобилось перенести эту сцену на экран, нужно было бы представить также упомянутую Х. Смитом “communal warmth" якутского кафе 1970-Х гг. и детали чаепития (“piping hot tea”). Не меньше проблем возникло бы и при воссоздании одежды участников данной мизансцены, которые "surrendered any semblance of fashion". Что касается "brandy" = "a strong alcoholic drink made from wine" (LDCE), то в англоязычных текстах это слово обычно заменяет французское "cognac", а значит потребовались бы специальные консультации, чтобы выяснить, что на самом деле пили в Якутии рабочие в период «развитого социализма».

Результат подобного воспроизведения англоязычного описания русской культуры нередко бывает печальным, и это мы прекрасно знаем по западным экранизациям русской классики.

\section{0. Заключение: «Кривое зеркало» межкультурной коммуникации}

Сказанное позволяет нам сделать вывод, что восприятие иноязычного описания культуры в значительной степени подвержено субъективным факторам семантической адаптации словарного состава языка описания в процессе его переориентации на иноязычную культуру в сочетании со стереотипом данной культуры, поддерживаемым обществом и индивидуальности адресата информации. Предстоит еще осуществить изучение сочетания многообразных факторов, которые влияют на адресата, приступающего к изучению англоязычного описания русской (или любой иной) культуры. Интерпретация слов, даже, казалось бы, присутствующих в исходной и принимающей культурах, подвержена разным прагматическим и семантическим процессам. Бесспорным остается факт неизбежной адаптации слова в новой для него культурно-языковой среде. Лингвистам, переводчикам, пользователям языка приходится внимательно следить за проявлениями такой адаптации, как и за динамикой изменения языка, ибо, как верно утверждает Линн Виссон, «<и>спользование любого новшества в языке во многом зависит от тона и точного стилистического контекста. Неправильное употребление иностранного слова может привести к курьезам, недопониманию и недоразумениям, а иногда даже к обидам, или вызвать смех у слушателей» (Виссон 2010: 18). Культурно-прагматическая адаптация, являющаяся результатом столкновения «двух противоположных векторов - культурной унификации, с одной 
стороны, и своеобразного культурного национализма, с другой» (Павловская 2020: 9) приводит к непониманию и даже межкультурным конфликтам. Именно на решение такого рода проблем направлены усилия исследователей интерлингвокультурологии и контактной вариантологии, новых дисциплин, развивающихся в междисциплинарном направлении.

(C) Victor V. Kabakchi and Zoya G. Proshina, 2021
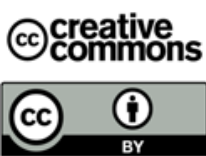

This work is licensed under a Creative Commons Attribution 4.0 International License https://creativecommons.org/licenses/by/4.0/

\section{СПИСОК ЛИТЕРАТУРЫ / REFERENCES}

Акуленко В.В. О «ложных друзьях переводчика» // Англо-русский и русско-английский словарь «ложных друзей переводчика» / Сост. В.В. Акуленко, С.Ю. Комиссарчик, Р.В. Погорелова, В.Л. Юхт; под общ. рук. В.В. Акуленко. М.: Советская энциклопедия, 1969. С. 371-384. [Akulenko, Valerii V. 1969. O "lozhnykh druz'yakh perevodchika" (On 'translator's false friends"). In V.V. Akulenko (ed.), S.Yu. Komissarchik, R.V. Pogorelova, V.L. Yukht. Anglo-russkii i russko-angliiskii slovar' "lozhnykh druzei perevodchika" (English-Russian and Russian-English Dictionary of "Translator's False Friends"), 371-384. Moscow: Sovetskaya Ehntsiklopediya].

Бархударов Л.С. Язык и перевод (Вопросы общей и частной теории перевода). М.: Международные отношения, 1975. 240 с. [Barkhudarov, Leonid S. 1975. Yazyk i perevod: Voprosy obshchei $i$ chastnoi teorii perevoda (Language and Translation: Issues of General and Specific Translation Studies). Moscow: Mezhdunarodnye Otnosheniya].

Бельчиков Ю.А. Интернационализмы // Лингвистический энциклопедический словарь / Под ред. В.Н. Ярцевой. М.: Советская Энциклопедия, 1990. С. 197. [Bel'chikov, Yurii A. 1990. Internatsionalizmy (Internationalisms). In Victoriya N. Yartseva (ed.). Lingvisticheskii ehntsiklopedicheskii slovar' (Linguistic Encyclopedic Dictionary), 197. Moscow: Sovetskaya Ehntsiklopediya].

Берков В.П. Слово в двуязычном словаре. Таллин: Валгус, 1977. 140 с. [Berkov, Valerii P. 1977. Slovo v dvuyazychnom slovare (A Word in a Bilingual Dictionary). Tallin: Valgus.]

Бурак А.Л. Translating Culture. Перевод и межкультурная коммуникация-1 Слова. М.: Р. Валент, 2010. 216 с. [Burak, Alexander L. 2010. Translating Culture. Perevod $i$ mezhkul'turnaya kommunikatsiya-1 Slova (Translation and Intercultural Communication-1. Words). Moscow: R. Valent].

Виссон Л. Русские проблемы в английской речи: Слова и фразы в контексте двух культур. = Where Russians Go Wrong in Spoken English: Words and Expressions in the Context of Two Cultures / Пер. с англ. М.: Р. Валент, 2003. 192 с. [Visson, Lynn. 2003. Where Russians Go Wrong in Spoken English: Words and Expressions in the Context of Two Cultures. Moscow: R. Valent].

Виссон Л. Слова-хамелеоны и метаморфозы в современном английском языке. М.: Р. Валент, 2010. 160 c. [Visson, Lynn. 2010. Chameleon Words and Metamorphoses in Modern English. Moscow: R. Valent].

Витгенштейн Л. Логико-философский трактат. М.: Изд-во иностр. лит., 1958. 133 с. [Wittgenstein, Ludwig. 1958. Logiko-filosofskii traktat (Tractatus Logico-Philosophicus). Moscow: Foreign Literature Publ.]. 
Вишнякова О.Д. Язык как инструмент смысловой интерпретации (на материале современного английского языка) // Вестник Московского ун-та. Сер. 19. Лингвистика и межкультурная коммуникация. 2018. № 1. С. 17-27. [Vishnyakova, Olga D. 2018. Yazyk kak instrument smyslovoi interpretatsii: na materiale sovremennogo angliiskogo yazyka (Language as an instrument of sense interpretation: based on Modern English). Moscow University Bulletin. Series 19: Linguistics and Intercultural Communication 1. 17-27].

Гумбольдт В. Избранные труды по языкознанию. М.: Прогресс, 1984. 397 с. [Humboldt, Wilhelm von. 1984. Izbrannye trudy po yazykoznaniyu (Selected Works in Linguistics). Moscow: Progress].

Едличко А.И. Семантика политических интерлексем в статике и динамике: на материале русского, немецкого и английского языков: дис. ... канд. филол. наук. М.: МГУ имени М.В. Ломоносова, 2009. 226 с. [Edlichko, Angela I. 2009. Semantika politicheskikh interleksem $v$ statike $i$ dinamike: na materiale russkogo, nemetskogo $i$ angliiskogo yazykov (Semantics of Political Interlexemes in Statics and Dynamics: Based on Russian, German and English). PhD dissertation. Moscow: Lomonosov Moscow State University].

Кабакчи В.В. Семантика политического термина // Лексическая, категориальная и функциональная семантика / И.К.Архипов, К.А.Гузеева, Н.Н.Кириллова (ред.). Л.: ЛГПИ, 1990. С. 38-44. [Kabakchi, Victor V. 1990. Semantika politicheskogo termina (Political term semantics). In I.K. Arkhipov, K.A. Guzeyeva, N.N. Kirillova (eds.), Leksicheskaya, kategorial'naya i funktsional'naya semantika (Lexical, Categorial, and Functional Semantics) Leningrad: Leningrad State Pedagogical Institute].

Кабакчи B.B. Rossija? (опыт интерлингвистического анализа) // Проблемы истории, филологии, культуры. Межвузовский сборник, вып. 3. / РАН Институт археологии, Магнитогорский государственный педагогический институт. М., 1996. С. 316-322. [Kabakchi, Victor V. Rossija? (opyt interlingvisticheskogo analiza) (Interliguictic analysis). In Problemy istorii, filologii, kul'tury (Problems of History, Philology, and Culture) 3. Archeology Institute, Russian Academy of Sciences, and Magnitogorsk State Pedagogical Institute. 316-322].

Кабакчи В.В. Основы англоязычной межкультурной коммуникации. СПб.: Изд-во РГПУ имени А. И. Герцена, 1998. 232 с. [Kabakchi, Victor V. 1998. Osnovy angloyazychnoi mezhkul'turnoi kommunikatsii (Fundamentals of the English Language Intercultural Communication). St. Petersburg: Herzen Russian State Pedagogical University].

Кабакчи В.В. Функциональный дуализм языка и языковая конвергенция (опыт моделирования языковой картины земной цивилизации) // Когнитивная лингвистика: ментальные основы и языковая реализация. Ч. 2: Текст и перевод в когнитивном аспекте. Сб. статей к юбилею профессора Н.А. Кобриной. / Отв. ред. Н. А. Абиева, Е. А. Беличенко. СПб.: Тригон, 2005. С. 164-175. [Kabakchi, Victor V. 2005. Funktsional'nyi dualizm yazyka i yazykovaya konvergentsiya: opyt modelirovaniya yazykovoi kartiny zemnoi tsivilizatsii (Language functional dualism and language convergence: Modeling language world view of the terrestrial civilization). In N. A. Abieva, E. A. Belichenko (eds.). Kognitivnaya lingvistika: mental'nye osnovy $i$ yazykovaya realizatsiya (Cognitive Linguistics: Mental Fundamentals and Language Actualization). Part 2: Tekst i perevod v kognitivnom aspekte (Text and Translation in the Cognitive Aspect). Collection dedicated to Prof. N.A. Kobrina. Saint Petersburg: Trigon].

Кабакчи В.В. Введение в интерлингвокультурологию // Язык и межкультурная коммуникация: материалы Второй Международной науч.-практ. конф., Великий Новгород, 19-20 мая 2011 г.: в 2 т. Т. 1 / отв. ред. О. А. Александрова, Е. Ф. Жукова. Новгород: Изд-во НовГУ имени Ярослава Мудрого, 2011. С. 11-19. [Kabakchi, 
Victor V. 2011. Vvedenie v interlingvokul'turologiyu (Introduction to Interlinguoculturology). In O.A. Aleksandrova, E.F. Zhukova (eds.). Yazyk $i$ mezhkul'turnaya kommunikatsiya (Language and Intercultural Communication) Proceedings of the Second International Conference, Velikii Novgorod, 19-20 May 2011. In 2 vol., vol. 1. Novgorod: Yaloslavl Mudryi Novgorod State University].

Кабакчи В.В., Белоглазова Е.В. Введение в интерлингвокультурологию. 2-е изд., испр. и доп. Москва: Юрайт, 2020. 250 с. [Kabakchi, Victor V. \& Elena V. Beloglazova. 2020. Vvedenie $v$ interlingvokul'turologiyu (Introduction to Interlinguoculturology). $2^{\text {nd }}$ edn., revised. Moscow: Yurait].

Кабакчи В.В., Юзефович Н.Г. Транслитерация русизмов в англоязычном описании русской культуры (к столетию поисков системы транслитерации русизмов) // Социальные и гуманитарные науки на Дальнем Востоке. 2007. № 3 (15). С. 115-124. [Kabakchi, Victor V. \& Natalia G. Yuzefovich. 2007. Transliteratsiya rusizmov v angloyazychnom opisanii russkoi kul'tury: $\mathrm{k}$ stoletiyu poiskov sistemy transliteratsii rusizmov (Transliteration of Russianisms in the English language description of the Russian culture: Dedicated to the hundredth anniversary of the search for Russian loan transliteration). The Humanities and Social Sciences in the Far East 15 (3). 115-124].

Мартине А. Основы общей лингвистики // Новое в лингвистике. Вып.3 / Сост. и ред. В. А. Звегинцев. М.: Прогресс, 1963. С. 366-566. [Martinet, André. 1963. Osnovy obshchei lingvistiki (Fundamentals of General Linguistics). In V. A. Zvegintsev (ed.), Novoe v lingvistike (New in Linguistics), 366-566. Part 3. Moscow: Progress].

Никитин М.В. Лексическое значение слова: Структура и комбинаторика. М.: Высшая школа 1983. 127 c. [Nikitin, Mikhail V. 1983. Leksicheskoe znachenie slova: Struktura $i$ kombinatorika (Lexical Meaning of a Word: Structure and Combinations). Moscow: Vysshaya shkola].

Никитин М.В. Курс лингвистической семантики. СПб.: Науч. Центр проблем диалога, 1996. 760 c. [Nikitin, Mikhail V. 1996. Kurs lingvisticheskoi semantiki (Course in Linguistic Semantics). Saint Petersburg: Research Center for Dialogue].

Павловская А.В. Глобальное vs региональное: к вопросу о проблемах межкультурной коммуникации в глобальном мире // Вестник Московского ун-та. Сер. 19. Лингвистика и межкультурная коммуникация. 2020. № 1. С. 9-21. [Pavlovskaya, Anna V. 2020. Global'noe vs regional'noe: K voprosu o problemakh mezhkul'turnoi kommunikatsii $\mathrm{v}$ global'nom mire (On challenges of intercultural communication in the global world). Moscow University Bulletin. Series 19. Linguistics and Intercultural Communication 1. 9-21].

Панов Е.Н. Язык человека и сигнальные системы животных: Обзор материалов круглого стола «Коммуникация человека и животных: взгляд лингвиста и биолога» / Институт проблем экологии и эволюции РАН. 2007. [Panov, Evgenii N. 2007. Yazyk cheloveka i signal'nye sistemy zhivotnykh: Obzor materialov kruglogo stola «Kommunikatsiya cheloveka i zhivotnykh: vzglyad lingvista i biologa» (Human language and signal systems of animals: Review of the Round Table "Communication of human beings and animals: view of a linguist and a biologist"). Institute of Ecology and Evolution, Russian Academy of Sciences]. URL: https://evolbiol.ru/document/1270 (accessed 03.07.2020).

Пауль Г. Принципы истории языка. / Пер. с нем. Под ред. А. А. Холодовича. М.: Иностр. литература, 1960. 499 c. [Paul, Hermann. 1960. Printsipy istorii yazyka (Principles of the History of Language). Moscow: Foreign Literature Publ.].

Прошина 3.Г. Контактная вариантология английского языка - основа для опосредованного перевода // Язык. Культура. Общение: Сборник научных трудов в честь юбилея заслуженного профессора МГУ имени М.В. Ломоносова С.Г. Тер-Минасовой. / Отв. 
ред. Г.Г. Молчанова. М.: Гнозис, 2008. С. 198-207. [Proshina, Zoya G. 2008. Kontaktnaya variantologiya angliiskogo yazyka - osnova dlya oposredovannogo perevoda (The World Englishes paradigm as a basis for intermediary translation). In Galina G. Molchanova (ed.), Yazyk. Kul'tura. Obshchenie: Sbornik nauchnykh trudov v chest' yubileya zasluzhennogo professora MGU imeni M.V. Lomonosova S.G. Ter-Minasovoi (Language. Culture. Communication: Collection of research articles dedicated to LMSU Honorary Professor Svetlana G. Ter-Minasova), 198-207. Moscow: Gnozis].

Прошина 3.Г. Контактная вариантология английского языка. Проблемы теории. World Englishes Paradigm. М.: Флинта: Наука, 2017. 208 с. [Proshina, Zoya G. 2017. Kontaktnaya variantologiya angliiskogo yazyka. Problemy teorii. (World Englishes Paradigm. Theoretical Issues.) Moscow: Flinta: Nauka].

Прошина 3.Г. Интерлингвокультурология и контактная вариантология английского языка // Лингвистика в эпоху глобанглизации: Сб. статей к юбилею В.В. Кабакчи. / Под ред. Е.В. Белоглазовой. СПб.: Изд-во СПбГЭУ, 2018. С. 86-93. [Proshina, Zoya G. 2018. Interlingvokul'turologiya i kontaktnaya variantologiya angliiskogo yazyka (Interlinguoculturology and the World Englishes Paradigm). In Elena V. Beloglazova (ed.) Lingvistika v ehpokhu globanglizatsii: Sbornik statei k yubileyu V.V. Kabakchi (Linguistics in the epoch of globanglization: Collection of articles dedicated to Victor V. Kabakchi), 86-93. Saint Petersburg: SPb State University of Economics].

Прошина 3.Г. Теория перевода. 4-е изд., испр. и доп. М.: Юрайт, 2019. 320 с. [Proshina, Zoya G. 2019. Teoriya perevoda (Translation Theory). $4^{\text {th }}$ edn, revised. Moscow: Yurait]. Прошина 3.Г. Межкультурная коммуникация: Английский язык и культура народов Восточной Азии. 2-е изд., испр. и доп. М.: Юрайт, 2020. 399 с. [Proshina, Zoya G. 2020. Mezhkul'turnaya kommunikatsiya: Angliiskii yazyk $i$ kul'tura narodov Vostochnoi Azii. (Intercultural Communication: English and Culture of East Asia). $2^{\text {nd }}$ edn., revised. Moscow: Yurait].

Рецкер Я.И. Теория перевода и переводческая практика: Очерки лингвистической теории перевода. М.: Р. Валент, 2004. 240 с. [Retsker, Yakov I. 2004. Teoriya perevoda $i$ perevodcheskaya praktika: Ocherki lingvisticheskoi teorii perevoda (Translation Theory and Practice: Essays on the Linguistic Theory of Translation). Moscow: R. Valent].

Свадост Э.П. Как возникает всеобщий язык? / АН СССР, Ин-т философии. М.: Наука, 1968. 287 c. [Svadost, Ehrmar P. 1968. Kak voznikaet vseobshchii yazyk? (How does a worldwide language emerge?) Moscow: Nauka].

Boulding, Kenneth E. 1976. Foreword. In John C. Condon \& Mitsuko Saito. Communicating Across Cultures for What? A Symposium on humane responsibility in intercultural communication, i-iii. Tokyo: Simul Press.

Crystal, David. 1997. English as a Global Language. Cambridge: Cambridge University Press. Haugen, Einar. 1966. Language Conflict and Language Planning: The Case of Modern Norwegian. Cambridge, MA: Harvard University Press.

Holliday, Adrian. 2006. Native Speakerism. ELT Journal 60 (4). 385-387.

Kachru, Braj B. 1980. The new Englishes and old dictionaries: Directions in lexicographical research on non-native varieties of English. In L. Zgusta (ed.), Theory and Method in Lexicography: Western and non-Western perspectives, 71-101. Columbia, SC: Hornbeam Press.

Kachru, Braj B. 1992. Meaning in deviation: Toward Understanding Non-Native English Texts. In Braj B. Kachru (ed.), The Other Tongue: English Across Cultures. $2^{\text {nd }}$ edn, 301-326. Urbana \& Chicago: University of Illinois Press.

Kachru, Braj B. 1998. English is an Asian language. Links and Letters 5. 89-108. 
Lovtsevich, Galina N. \& Alexander A. Sokolov. 2020. World Englishes and learner lexicography: View from the Expanding Circle. The Russian Journal of Linguistics 24 (3). 703-721.

McCaughey, Kevin. 2005. The kasha syndrome: English language teaching in Russia. World Englishes 24 (4). 455-459.

Newmark, Peter. 1988. A Textbook of Translation. New York a.o.: Prentice Hall.

Proshina, Zoya G. \& Anna A. Eddy (eds.). 2016. Russian English: History, Functions, and Features. Cambridge: Cambridge University Press.

Pym, Anthony. 2010. Exploring Translation Theories. London \& New York: Routledge.

Sdobnikov, Vadim V. 2019. Translation Studies today: Old problems and new challenges. Russian Journal of Linguistics 23 (2). 295-327.

Seidlhofer, Barbara. 2011. Understanding English as a Lingua Franca. Oxford: Oxford University Press.

Smith, Larry E. 2008. Familiar issues from a World Englishes perspective. In Zoya Proshina (еd.), Культурно-языковые контакты. Вып. 10 Владивосток: Изд-во ДВГУ. C. 67-73. [Kul'turno-yazykovye kontakty Vyp. 10. (Culture and Language Contacts. Part 10), 67-73. Vladivostok: Far Eastern Univ. Press]. Reprint: Вестник РУДН. Сер. Вопросы образования: Языки и спещиальность. 2016. № 1. С. 14-18. [Bulletin of the Russian University of Peoples' Friendship. Series: Education Issues: Languages and Speciality 1. 2016, 14-18].

\section{Словари / Dictionaries}

Ахманова О.С. Словарь лингвистических терминов. М.: Советская Энциклопедия, 1966. 607 c. [Akhmanova, Olga S. 1966. Slovar' lingvisticheskikh terminov (Dictionary of Linguistic Terms). Moscow: Sovetskaya Ehntsiklopediya].

АРиРАСЛДП - Англо-русский и русско-английский словарь «ложных друзей переводчика» / Сост. В.В. Акуленко, С.Ю. Комиссарчик, Р.В. Погорелова, В.Л. Юхт; под общим рук. В.В. Акуленко. М.: Советская энциклопедия, 1969. 384 с. [V.V. Akulenko (ed.), S.Yu. Komissarchik, R.V. Pogorelova \& V.L. Yukht. 1969. Anglo-russkii i russkoangliiskii slovar' "lozhnykh druzei perevodchika" (English-Russian and Russian-English Dictionary of “Translator's False Friends"). Moscow: Sovetskaya Ehntsiklopediya].

Дьяков А.И. Словарь англицизмов русского языка. Новосибирск, 2014. URL: http://anglicismdictionary.ru/ (дата вхождения 17 июня 2020). [D'yakov, Anatolii I. 2014. Slovar' anglitsizmov russkogo yazyka (Dictionary of Anglicisms in the Russian Language). Novosibirsk. URL: http://anglicismdictionary.ru/ (accessed 17 June 2020)].

ЛЭС - Лингвистический энциклопедический словарь / Под ред. В.Н. Ярцевой. М.: Советская Энциклопедия, 1990. 685 с. [Victoria N. Yartseva (ed.). 1990. Lingvisticheskii ehntsiklopedicheskii slovar' (Linguistic Encyclopedic Dictionary). Moscow: Sovetskaya Ehntsiklopediya]

НБРАС - Новый большой русско-английский словарь. В 3х томах. / Под общим рук. П.Н. Макурова, М.С. Мюллера, В.Ю. Петрова. М.: Лингвистика, 1997. [Makurov P.N., M.S. Myuller, \& V.Yu. Petrov. 1997. Novyi bol'shoi russko-angliiskii slovar' (New Great Russian-English Dictionary). In 3 volumes. Moscow: Lingvistika].

ССЛТ - Словарь социолингвистических терминов / Под ред. В.Ю. Михальченко. М.: РАН. ИЯ. Российская академия лингвистических наук. 2006. 312 с. [V. Yu. Mikhal'chenko (ed.). 2006. Slovar' sotsiolingvisticheskikh terminov (Dictionary of Sociolinguistic Terms). Moscow: Institute of Linguistics, Russian Academy of Sciences; Russian Academy of Linguistic Studies]. 
ТСРЯ - Ожегов С.И., Шведова Н.Ю. Толковый словарь русского языка. 4-е изд. М.: Азбуковник, 2000. 944 с. [Ozhegov, Sergei I. \& NataliaYu. Shvedova. 2000. Tolkovyi slovar' russkogo yazyka (Dictionary of the Russian Language). $4^{\text {th }}$ edn. Moscow: Azbukovnik].

CED - Cambridge English Dictionary. 2020. URL: https://dictionary.cambridge.org/ru/словарь (13.07.2020).

CIDE - Cambridge International Dictionary of English. 1995. Cambridge: Cambridge University Press.

LDCE - Longman Dictionary of Contemporary English. $4^{\text {th }}$ edn. London: Pearson Education, 2006. URL: https://www.ldoceonline.com

OALD - Oxford Advanced Learner's Encyclopedic Dictionary. Oxford: Oxford University

Press, 1992. URL: https://www.oxfordlearnersdictionaries.com

OED2 Online 2013 - Oxford English Dictionary Online. Oxford: Oxford University Press, 2013. URL: http://oxforddictionaries.com/

OEED - Oxford Encyclopedic English Dictionary / J.M.Hawkins, R.Allen (eds.). Oxford: Clarendon Press, 1991.

\section{Источники примеров}

Агни Лев. Демократия Запада. // Проза.py. 2011. [Agni Lev. Demokratiya Zapada. (Democracy of the West)] URL: https://proza.ru/2011/03/20/259 (дата обращения: 10.07.2020).

Википедия. 2020. URL: https://ru.wikipedia.org/wiki/Честолюбие (дата обращения 10.07.2020)

Психология и психиатрия. 2020. [Psikhologiya i psikhiatriya (Psychology and psychiatrics)]

URL: https://psihomed.com/ambitsii/ (дата обращения 10.07.2020).

Романов С.К. Русский Лондон. М.: АСТ: Астрель, 2009. 480 с. [Romanov, S.K. 2009.

Russkii London. (Russian London). Moscow: AST: Astrel'].

Canadian Tribune. 1988. 29.02.

Chamberlain, Lesley. The Food and Cooking of Russia. Harmondsworth: Penguin, 1983.

Davidow, Mike. People's Theater: From the Box Office to the Stage. Moscow: Progress, 1977. Encyclopoedia Britannica 2001. Standard edn. CD-ROM.

Fleer, Marilyn \& Bert van Oers. 2018. International Handbook of Early Childhood Education. Dordrecht: Springer.

Fodor's Moscow and St. Petersburg. $4^{\text {th }}$ edn. Fodor's Travel Publications, 1999.

(The) Guardian, 07 Feb. 2003.

Hughes, Lindsey. 1998. Russia in the Age of Peter the Great. New Haven: Yale University Press.

Jack, Andrew. 2005. Inside Putin's Russia: Can There Be Reform without Democracy? Oxford: Oxford University Press.

Kelly, Catriona. 2016. St Petersburg: Shadows of the Past. New Haven: Yale University Press.

Laszio, Ervin \& Joel Kurtzman (eds.). 1981. Political and Institutional Issues of New International Economic Order. New York: Pergamon Press.

Lear, John. 1986. Death in Leningrad. London: Pluto Press.

Meier, Andrew. 2004. Black Earth. Russia After the Fall. Harper Perennial, UK.

Nabokov V. 1990. Selected Prose and Verse. Moscow: Raduga.

Pray, Eleanor Lord. 2019. Selected Letters. 1907-1917. Edited, with introductions and notes by Birgitta Ingemanson. Vladivostok: Rubezh.

Rutherford, Edward. 1992 Russka. London: Arrow Books, UK. 
Smith, Hendrick. 1976. The Russians. London: Sphere Books, 1976.

SPbTimes - Saint Petersburg Times. 2000; 2013; 2014.

Stevenson, Krista, Dicker Mike, Song Li, Zhang Jin, Jia Xuerui, Fu Li \& Liu Aihua. 2005. Highlights of Chinese Culture. Beijing: Hitpress.

Turgenev, Ivan S. 1965. Fathers and Sons. Trans. R. Edmonds. Harmondsworth: Penguin. Vapnyar, Lara. 2003. There Are Jews in My House: Stories. New York: Anchor Books.

Yershov, Pavel. 1988. The Little Humpbacked Horse. Tr. by Louis Zellikoff. Moscow: Raduga, 1988. Available at: http://lib.ru/LITRA/ERSHOW/horse.txt (accessed 07 July 2020).

Wikipedia: village 2020, URL: https://en.wikipedia.org/wiki/Village (accessed 16 July 2020) Wilson, Mitchell. 1961. Meeting at a Far Meridian. New York: Doubleday.

\section{Article history:}

Received: 19 July 2020

Accepted: 22 December 2020

\section{История статьи:}

Дата поступления в редакцию: 19 июля 2020

Дата принятия к печати: 22 декабря 2020

\section{Bionotes:}

Viktor V. KABAKCHI, Dr. habil., Professor at the Translation Department of the Herzen State Pedagogical University of Russia (Herzen University). He is engaged in the field of the Russian-Culture-Oriented English. He is the founder of an innovative branch of linguistics - "interlinguaculturology" and the author of about 200 publications published in Russia, UK, USA, Cyprus and Germany. He has compiled The Dictionary of Russia (2,500 cultural terms, 2002). Professor V. Kabakchi's followers have successfully carried out research in the field of English-language descriptions of the Spanish-speaking culture of the United States, the culture of Ghana, and the Republic of Tuva, as well as a fundamental study of the features of the English-language description of various aspects of Russian culture, including Russian Orthodoxy.

\section{Contact information:}

48-50-52, Nab. Moika river, St. Peterburg, 196653, Russia e-mail:vkabakchi@gmail.com

ORCID: 0000-0003-2164-7017

Zoya G. PROSHINA is Professor in the Faculty of Foreign Languages and Area Studies at Lomonosov Moscow State University, Russia, and was Professor in the Department of Linguistics and Intercultural Communication Studies at Far Eastern Federal University, Vladivostok, Russia. She was President of the International Association for World Englishes (2011-2012). She authored about 300 works. Her research interests are language contacts, world Englishes, sociolinguistics and translation studies.

\section{Contact information:}

1, bld. 13, Leninskiye Gory, Moscow, 119991, Russia

e-mail: proshinazoya@yandex.ru

ORCID: 0000-0002-0570-2349 


\section{Сведения об авторах:}

Виктор Владимирович КАБАКЧИ - доктор филологических наук, профессор кафедры перевода Российского государственного педагогического университета им. А.И. Герцена; работает в области англоязычного описания русской культуры. Основал инновационное направление в лингвистике - интерлингвокультурологию, изучающую иноязычное описание культуры. Автор около 200 опубликованных работ (СССР-Россия, США, Великобритания, Кипр), среди которых монографии, учебные пособия, словарь “The Dictionary of Russia" (2002) и многочисленные статьи. Ученики его школы успешно осуществили исследования в области англоязычного описания испаноязычной культуры США, культуры Ганы и Республики Тува, англоязычного описания различных аспектов русской культуры, включая Русское Православие.

\section{Контактная информация:}

Россия, Санкт-Петербург, 196653, Наб. реки Мойки, 48-50-52

e-mail:vkabakchi@gmail.com

ORCID: 0000-0003-2164-7017

Зоя Григорьевна ПРОШИНА - доктор филологических наук, профессор кафедры теории преподавания иностранных языков факультета иностранных языков и регионоведения Московского государственного университета имени М.В. Ломоносова. Была Президентом Международной ассоциации исследователей вариантов английского языка (2011-2012). Является автором около 300 научных работ: книг, словарей, статей. Ее научные интересы лежат в области языковых контактов, вариантов английского языка, социолингвистики, переводоведения.

\section{Контактная информация:}

МГУ имени М.В. Ломоносова, Факультет иностранных языков и регионоведения Россия, Москва, 119991, Ленинские горы, 1, стр. 13

e-mail: proshinazoya@yandex.ru

ORCID: 0000-0002-0570-2349 